\title{
Racial Identity, Phenotype, and Self-Esteem Among Biracial Polynesian/White Individuals
}

\author{
Kawika Allen \\ Brigham Young University, gekawika_allen@byu.edu \\ Patton O. Garriott \\ University of Missouri \\ Carla J. Reyes \\ Catherine Hsieh \\ University of Missouri
}

Follow this and additional works at: https://scholarsarchive.byu.edu/facpub

Part of the Mental and Social Health Commons, and the Social and Behavioral Sciences Commons

\section{BYU ScholarsArchive Citation}

Allen, Kawika; Garriott, Patton O.; Reyes, Carla J.; and Hsieh, Catherine, "Racial Identity, Phenotype, and Self-Esteem Among Biracial Polynesian/White Individuals" (2017). Faculty Publications. 3182. https://scholarsarchive.byu.edu/facpub/3182 accepted for inclusion in Faculty Publications by an authorized administrator of BYU ScholarsArchive. For more information, please contact ellen_amatangelo@byu.edu. 


\author{
G. E. KawiKa Allen Southern Utah University \\ PATTON O. GARRIOTT University of Missouri* \\ CARla J. ReYes Private Practitioner** \\ CATHERINE HSIEH University of Missouri***
}

\title{
Racial Identity, Phenotype, and Self-Esteem Among Biracial Polynesian/White Individuals
}

This study examined racial identity, self-esteem, and phenotype among biracial Polynesian/White adults. Eighty-four Polynesian/White persons completed the Biracial Identity Attitude Scale, the Rosenberg Self-Esteem Inventory, and a Polynesian phenotype scale. Profile analyses showed participants identified more with their Polynesian parent. A mediation analysis revealed that phenotype did not mediate the relationship between biracial identity and selfesteem.

Throughout the 20th century, the United States has experienced dramatic increases in racial and ethnic diversity (Cobb-Clark \& Kossoudji, 2000; Greenless \& Saenz, 1999; Root, 1996; U.S. Census Bureau, 2009). Racial and ethnic minorities comprise approximately one third of the U.S. population and are expected to become

Department of Psychology, Southern Utah University, 351 West University Boulevard, GC 310B, Cedar City, UT 84720 (GEKawikaAllen@suu.edu).

*University of Missouri, 16 Hill Hall, Columbia, MO 65211.

**3461 Monte Verde Dr., Salt Lake City, UT 84109.

*** University of Missouri, 16 Hill Hall, Columbia, MO 65211.

Key Words: biracial identity, multiracial, phenotype, Polynesian/White, self-esteem. the majority in 2042 (Bernstein \& Edwards, 2008). Following this trend, there have been increases in interracial unions and births in the United States. Currently, approximately 5.2 million individuals self-identify as multiracial, representing a $33 \%$ population increase since the year 2000 (U.S. Census Bureau, 2009). Multiracial individuals are unique because of their diverse backgrounds regarding race, culture, and identity, and the intersection of these constructs could present certain psychological challenges throughout their lifetime (Shih \& Sanchez, 2005). Documented increases in the multiracial population enhance the probability that helping professionals will interact with multiracial individuals and therefore call for psychologists, psychiatrists, social workers, teachers, and other human service agencies to increase their understanding of issues salient to this population (Root, 1996). Although there are an increasing number of multiracial individuals in the United States, there are many specific multiracial populations that have not been given sufficient attention and warrant further investigation. Therefore, the purpose of the present study was to examine interrelations between racial identity and psychological adjustment in a specific and seldom studied population - biracial Polynesian/White individuals. (We use the terms biracial and multiracial 
interchangeably to capture the multiple racialized categories that individuals in the general population may use to identify themselves and to reflect the fact that participants in our sample identified with only two racialized categories.)

The South Pacific Islander (commonly known as Polynesians) population in the United States has exponentially increased over the years (Allen \& Heppner, 2011). Most of the Polynesians who immigrated from the South Pacific region to the United States consist of (but not limited to) those from the Kingdom of Tonga, Western and American Samoa, and New Zealand. This South Pacific region is also commonly known as the Polynesian triangle, stretching from New Zealand to Easter Island and then north to Hawaii. Each island consists of a specific and different group of people, culture, language, customs, and traditions that follow most typically a collectivistic family system (Allen \& Heppner, 2011). Furthermore, Polynesian subgroups have been described as sharing some similar cultural values and physical characteristics, including a matriarchal order to family structure, and a welcoming and generous community (Sobralske, 2006). Polynesians have since settled in various states of the United States, resulting in generations of American-born Polynesians. Currently, there are over 875,000 Polynesian individuals in the United States, with the largest concentrations in states such as California, Hawaii, Washington, Texas, and Utah (U.S Census Bureau, 2009). Furthermore, the U.S. Census Bureau estimates that approximately 115,000 Polynesians also identified as biracial, with two racial heritages (e.g., Polynesian/White). There has been some research focused on Pacific Islanders/Polynesians in the United States (Allen \& Heppner, 2011; McCubbin \& Dang, 2010; McCubbin, Ishikawa, \& McCubbin, 2007), but very little is known about Polynesians and their identity development, particularly those who are biracial Polynesian/White individuals.

Biracial and multiracial individuals present unique issues relevant to current conceptualizations of racial identity and associated psychological outcomes. For example, prior research suggests that the manner in which multiracial individuals choose to identify may be based upon a variety of factors, including context (e.g., Brunsma \& Rockquemore, 2001; Brusa, 2008; Cooke, 1997; Pedrotti, Edwards, \& Lopez, 2008; Phinney, 1992; Suzuki-Crumly \& Hyers,
2004), family influence (e.g., Crawford \& Alaggia, 2008), and ancestry (e.g., Khanna, 2008). Furthermore, although prior research has documented the link between more advanced racial identity statuses (Helms, 1997) and self-esteem among people of color and Whites, less is known regarding the relationship between racial identity and the self-esteem of multiracial individuals (Garriott, Love, \& Tyler, 2008; Parham \& Helms, 1985; Watt, 2006). Similarly, although previous research indicates that phenotype is related to self-esteem among people of color, how phenotype interacts with racial identity to impact self-esteem among multiracial individuals is not well understood (López, 2008). Thus, there is very little known and little research exists regarding the interaction between phenotype, racial identity, and self-esteem.

In a recent review of empirical studies devoted to multiracial status and psychological outcomes, Shih and Sanchez (2005) concluded that although multiracial individuals do not appear to suffer more psychologically than their monoracial peers, further research is required in order to examine unique factors that contribute to multiracial individuals' psychological adjustment (i.e., assimilation, identity, self-esteem). The authors specifically echoed past researchers' recommendations that phenotype (e.g., Rockquemore \& Brunsma, 2002) and gender (e.g., Cooney \& Radina, 2000) be examined as either moderator or mediator variables in future research with multiracial samples. Indeed, past research indicates that darker skin color is associated with more negative self-perceptions among some people of color and that gender may influence this relationship (Telzer \& Garcia, 2009).

In sum, research indicates that racial identity is related to the self-esteem, health, and well-being of persons of color and multiracial individuals. Furthermore, phenotype has been identified as a potential mediator of the relationship between racial identity and psychological outcomes. No studies, however, have investigated the relations among racial identity, phenotype, and self-esteem among biracial Polynesian individuals. To advance current understanding of multiracial individuals' psychological adjustment, this study examined the relationships between biracial identity, phenotype, and selfesteem in a sample of biracial Polynesian/White individuals. Gender differences in variables of interest were also tested in accord with past recommendations (e.g., Shih \& Sanchez, 2005) 
and research indicating gender differences in the effects of skin color on self-esteem, with females reporting a stronger relationship than males (Ramos, Jaccard, \& Guilamo-Ramos, 2003).

\section{Biracial Identity, Phenotype, and Self-esteem}

Biracial identity. Scholars have argued that current racial identity literature is lacking in attention to biracial identity development (Brusa, 2008; Root, 1996), whereas others have specifically investigated biracial identity development among persons of color (ChoiMisailidis, 2003; Jacobs, 1977, 1992; Kerwin \& Ponterotto, 1995; Kich, 1992; Poston, 1990). Furthermore, children with parents of two or more racial heritages may face unique psychosocial challenges as compared to their monoracial peers. One specific struggle that biracial individuals may encounter is pressure to affiliate with one racial group over another, also known as the forced-choice dilemma (Standen, 1996). Pressure to restrictively identify with one racial group may result in increased social anxiety and negative evaluation by others (Brunsma \& Roquemore, 2001; Coleman \& Carter, 2007). Results from a study conducted by Coleman and Carter showed that a validated biracial identity (i.e., biracial as validated by parents, caregivers, family, friends, and peers) may serve as a protective factor against anxiety and depressive symptoms. In contrast, biracial individuals who considered their racial backgrounds to be meaningless or depending on circumscribed factors reported higher levels of depression and trait anxiety symptoms. In another study, researchers found that multiracial adolescents who identified with multiple racial categories also reported equal or higher levels of self-esteem and social engagement compared to multiracial peers who identified with predominantly one racial category (Binning, Unzueta, Huo, \& Molina, 2009).

Family influence has been attributed to forming a positive and validated biracial identity (Coleman \& Carter, 2007; Crawford \& Alaggia, 2008). Specifically, biracial identity formation has been linked to three major themes regarding the family influence: (a) level of parental awareness and understanding of race issues, (b) impact of family structure, and (c) communication and willingness to talk about race issues. Existing studies in this area have shown that the more likely parents were aware of and understood racial issues and demonstrated willingness to dialogue with their children, the more likely a validated biracial identity was to be formulated (Crawford \& Alaggia, 2008).

Phenotype. Individuals who possess certain physical characteristics are often assumed to be members of certain racial groups. Therefore, the more a person's physical characteristics resemble that of a particular racial group, the more likely they are to identify or be identified with that racial group (Brusa, 2008; Cooke, 1997; Khanna, 2008). Biracial identity research illustrates that awareness of socioracial categories stems from the realization that visual differences exist between socially defined racial groups and an understanding of the perceptual cues utilized to categorize ethnicities and races (Koot \& Venema, 1985; Morganthau, 1995; Overmier, 1990; Spickard, 1989). For example, a study conducted by Brunsma and Rockquemore (2001) found that biracial individuals made racial identity orientation choices within situational cultural contexts by way of the participants' assumptions of how others perceived their appearance. In addition, there is a growing body of literature on skin tone and experiences of discrimination; effects of skin tone on racial attitudes; and relationship between skin tone, self-esteem, and racial identity, which can impact the intersections of biracial identity development, self-esteem, and overall psychological well-being and adjustment (Coard, Breland, \& Raskin, 2001; Keith, Lincoln, Taylor, \& Jackson, 2010).

Physical characteristics and the ambiguity of stereotypically associated features (i.e., "fine", vs. "coarse"' hair; long, straight nose vs. broad, flat nose) are two conditions that affect biracial individuals. Skin color, for example, has been cited as a critical factor contributing to racial and ethnic ambiguity. Specifically, light skin color has contributed to the "passing" phenomenon, which allows minority individuals to assimilate and be accepted into majority society on the basis of European physical features (i.e., light skin color, light eye color, and straight hair; Greene, 1994). Greene and Pasion-Gonzales (1994) noted that the ability to pass often plays an influential role in biracial individuals' development of circumstantial identities in which they are consciously and inconspicuously able to move in and out of many different 
social environments and cultures. Conversely, the ability to pass as White or European American may also contribute to psychological distress among multiracial individuals, as selfidentifying as a person of color (e.g., Asian, African American, Latina or Latino) may illicit negative evaluations from others who insinuate that the individual must justify their selfidentification (Shih \& Sanchez, 2005). Thus, studies that have been conducted on biracial identity include the element of phenotype (physical characteristics) as an indication of racial status (Brunsma \& Rockquemore, 2001; Greene, 1994). Little is known, however, about the phenotype of biracial Polynesian/White persons and how their physical appearance impacts their racial identity.

Self-esteem. Multiracial individuals may experience difficulty not only with identity confusion but also with low self-esteem due to marginalization and social isolation (Sue \& Sue, 2008). In addition, multiracial individuals may face challenges, including being compelled to justify identity choices, experiencing forced-choice dilemmas, a lack of positive multiracial role models, rejection from multiple racial groups, and conflicting messages from family members regarding race, all of which contribute to their sense of self-worth (Shih \& Sanchez, 2005). With regard to familial messages, multiracial children may experience identity confusion or low self-esteem should they not experience familial racial socialization.

Although previous studies have examined the link between monoracial individuals' racial identity and self-esteem, very little is known regarding self-esteem and racial identity among multiracial populations in general and Polynesian/White biracial individuals specifically (Brunsma \& Rockquemore, 2001; Brusa, 2008; Cooke, 1997; Crawford \& Alaggia, 2008; Khanna, 2008; Suzuki-Crumly \& Hyers, 2004). Available literature devoted to multiracial identity and self-esteem has produced mixed results. Specifically, whereas some studies have suggested that multiracial individuals experience lower levels of self-esteem than their monoracial peers, others have not supported this link (Gillem, Cohn, \& Throne, 2001; Hall, 1992). In a study conducted with 30 self-identified Black/Japanese adults, Hall (1992) found that participants generally reported high levels of self-esteem and appeared to feel positively regarding their physical appearance. Given past empirical and theoretical literature's assertions that biracial identity, physical appearance, and self-esteem may be interrelated (Binning et al., 2009; Ramos et al., 2003; Telzer \& Garcia, 2009), this study examined causal links between these variables.

\section{Purpose of the Study}

The present study explored the relations between biracial Polynesian/White individuals' biracial identity, subjective phenotype, and self-esteem. Specifically, this study attempted to answer the following research questions: (1) Do biracial Polynesian/White individuals' self-esteem and racial identity vary based on the gender of the participant's Polynesian parent? (2) Do biracial Polynesian/White individuals' self-esteem and racial identity status vary based on gender? (3) Does phenotype mediate the relationship between racial identity and self-esteem? With regard to the final research question, several hypotheses were made. Specifically, it was hypothesized that (3a) biracial identity would be a positive predictor of self-esteem, (3b) phenotype would be a negative predictor of self-esteem, (3c) biracial identity would be a positive predictor of phenotype, and ( $3 \mathrm{~d})$ the magnitude of the association between biracial identity and self-esteem would be reduced (mediated) by phenotype.

In addition, a particular strength of this study is the inclusion of the Polynesian biracial sample. Existing literature on multiracial individuals has investigated individuals of Asian American, African American, Native Americans, Latino and Latina, and European American heritages (Brunsma \& Rockquemore, 2001; Brusa, 2008; Cooke, 1997; Crawford \& Alaggia, 2008; Khanna, 2008; Phinney, 1992; Suzuki-Crumly \& Hyers, 2004). There remains, however, a lack of research on the identity development of biracial Polynesian/White people, who represent an increasing and seldom studied population in the United States (U.S. Census Bureau, 2009).

\section{METHOD \\ Participants}

Eighty-four individuals participated in the study, $54 \%(n=45)$ women and $46 \%(n=39)$ men, 
with a mean age of 28.6 years and an age range of $18-72$ years. Related to higher education, 35\% reported some college education, $25 \%$ indicated that they were still in college, $21 \%$ reported graduating from college, and $12 \%$ indicated receiving graduate and advanced professional degrees. Regarding the participants' biracial background, 38\% $(n=32)$ of the participants reported having Polynesian mothers and $62 \%(n=52)$ of the participants reported having Polynesian fathers. The following are descriptive data of different combinations of biracial Polynesian/White participants: Tongan/White, $17 \%(n=14)$, Samoan/White, $18 \%(n=15)$, Fijian/White, 5\% $(n=4)$, Maori/White, $4 \%$ $(n=3)$, two or more Polynesian races/White, $12 \%(n=10)$, and Niuean/White, $2 \%(n=2)$, and, the category most frequently reported by the participants, Hawaiian/White, $43 \%(n=36)$.

\section{Instruments}

Demographic questionnaire. The participants responded to items related to demographic information including their gender, age, ethnicity, parents' ethnicity, phenotype, education level, marital status, and occupation.

Biracial Identity Attitude Scale (BIAS; Cooke, 1997). The BIAS is an adaptation of the Multigroup Ethnic Identity Scale (MEIM; Phinney, 1992). The BIAS was normed on college undergraduates and high school students from various racial groups, specifically African American, Asian, Latino or Hispanic, and Native American (Cooke, 1997). It was developed to examine the ethnic identity of minority-majority biracial individuals by measuring individuals' biracial identity from the standpoint of their parents' racial heritage. The BIAS includes 20 items and four subscales: (a) affirmation and belonging $(\mathrm{AB})$ - how biracial individuals feel about membership in their parents' racial groups, (b) racial identity achievement (RIA) - biracial people's exploration of their cultural heritage, (c) racial group behavior (RGB) - biracial individuals' participation in cultural activities familiar to their parents' racial group, and (4) the other-group orientation (OGO) scale, which measures biracial people's interactions with racial groups other than their parents' groups. Participants completed the scale twice, once for each parent. Previous internal consistency estimates on BIAS subscale scores have ranged from .63 to .87 (Cooke, 1997). Cronbach's alphas on BIAS subscales for the current sample ranged from .10 to .83 . For the Paternal Racial Group scale: $\mathrm{AB}=.79$, RIA $=.10, \mathrm{RB}=.43$, and $\mathrm{OGO}=.35$. For the Maternal Racial Group scale: $\mathrm{AB}=.83$, RIA $=.12, \mathrm{RB}=.45$, and $\mathrm{OGO}$ $=.21$. Cronbach's alpha for full scale scores in the current sample was .81 .

Rosenburg Self-Esteem Inventory (RSE; Rosenberg, 1965). The RSE was used to measure self-esteem, as it has been frequently used with racially and ethnically diverse populations (Blascovich \& Tomaka, 1991; Hall, 1902; Phinney, 1992, 1996; Speight, 1996; Thrasher, 1994). The RSE consists of 10 Likert-type items designed to assess one's self-esteem with good internal reliability $(\alpha=.92)$ as well as test-retest reliability ( $\alpha=.85$ and $\alpha=.88)$. Chronbach's alpha for scale scores in the current study was .86 .

Phenotype. Participants were asked to report their perceptions of personal resemblance to Polynesian physical characteristics on a sixitem Likert-type scale ranging from 1 (no Polynesian resemblance) to 5 (Polynesian resemblance). We relied on self-reports from participants because this method has been successfully used in past research (Telzer \& Garcia, 2009) and out of our desire to understand how self-perceptions of physical appearance affected participants' ratings of selfesteem. Furthermore, we felt observer ratings of participants' physical appearance might be invasive and discourage participation in the study. Physical characteristics reported included skin color, hair texture, and facial features. Coefficient alpha for score on this scale was .85 .

\section{Procedure}

Participation was voluntary, and no monetary compensation was given. Adhering to institutional review board guidelines, participants were solicited from various settings from all over the Rocky Mountain region of the United States through mailers and flyers. In addition, announcements at cultural, civic, club, religious, college, and community associations and organizations were made, resulting in arranged meetings in a research office between the participants and the first author to facilitate participants' completion of the survey. A booth was also set up at 
Table 1. Descriptive Statistics of Participants' Rating of Their Polynesian Parents

\begin{tabular}{|c|c|c|c|c|}
\hline \multirow[b]{2}{*}{ Study Variables } & \multicolumn{2}{|c|}{ Polynesian Mother } & \multicolumn{2}{|c|}{ Polynesian Father } \\
\hline & $\begin{array}{l}\text { Female } \\
M(S D)\end{array}$ & $\begin{array}{c}\text { Male } \\
M(S D)\end{array}$ & $\begin{array}{l}\text { Female } \\
M(S D)\end{array}$ & $\begin{array}{c}\text { Male } \\
M(S D)\end{array}$ \\
\hline Self-esteem & $1.53(.43)$ & $1.27(.26)$ & $1.60(.53)$ & $1.54(.47)$ \\
\hline Affirmation and belonging & $3.62(.44)$ & $3.72(.35)$ & $3.59(.47)$ & $3.44(.65)$ \\
\hline Racial identity achievement & $2.79(.32)$ & $2.71(.32)$ & $2.81(.35)$ & $2.77(.35)$ \\
\hline Racial group behavior & $3.40(.47)$ & $2.85(.97)$ & $3.23(.75)$ & $2.86(.71)$ \\
\hline \multirow[t]{4}{*}{ Other group orientation } & $2.79(.34)$ & $2.78(.35)$ & $2.67(.35)$ & $3.64(.35)$ \\
\hline & \multicolumn{2}{|c|}{ White Mother } & \multicolumn{2}{|c|}{ White Father } \\
\hline & Female & Male & Female & Male \\
\hline & $M(S D)$ & $M(S D)$ & $M(S D)$ & $M(S D)$ \\
\hline Self-esteem & $1.53(.43)$ & $1.27(.26)$ & $1.60(.53)$ & $1.54(.47)$ \\
\hline Affirmation and belonging & $3.19(.70)$ & $3.21(.70)$ & $3.42(.54)$ & $3.52(.43)$ \\
\hline Racial identity achievement & $2.59(.34)$ & $2.55(.47)$ & $2.68(.44)$ & $2.65(.32)$ \\
\hline Racial group behavior & $2.69(.92)$ & $2.75(.83)$ & $3.18(.62)$ & $2.80(1.11)$ \\
\hline Other group orientation & $2.71(.28)$ & $2.62(.28)$ & $2.70(.34)$ & $2.66(.36)$ \\
\hline
\end{tabular}

various Polynesian festivals and events describing the study, and potential participants were invited to complete the survey packet. Surveys were returned to the researchers either via inperson collection or the mail. Of the 98 surveys returned, 14 questionnaires were excluded from the data analysis because of extensive missing values.

\section{RESULTS}

The descriptive statistics of participants' rating of their Polynesian and White parents (Table 1) are included. To preserve statistical power, we collapsed subgroups of participants into one group for primary analyses. The correlations of the study's variables by parental figure (Table 2) are also included. Examination of bivariate correlations showed statistically significant associations between paternal acceptance and belonging and phenotype as well as phenotype and selfesteem. None of the maternal subscales on the BIAS were significantly associated with phenotype or self-esteem. In addition, we conducted a multivariate profile analysis (an application of MANOVA), which allowed us to analyze several dependent variables simultaneously on the same scale. After conducting multivariate profile analyses with all BIAS subscales entered together as the dependent variable, there was a significant Parental Rating $\times$ Polynesian Parents interaction, $F(1,83)=11.94, p=.04$, indicating that all participants reported higher levels of racial identification with the parent who was Polynesian than with the parent who was White. We also analyzed profiles for each individual, which tests if there are differences in the levels or shapes of the profiles for male and female participants whose mother or father was Polynesian. This test for differences in the shape of profiles is known as the test of parallelism (a test for Group [or condition] $\times$ Scale interaction). The test of parallelism determined if the subgroups of biracial Polynesian individuals have the different patterns of highs and lows on the various subscales. After we conducted this test of differences, the findings suggest that female participants reported higher levels on BIAS subscales with their Polynesian parents (both father and mother) than the Polynesian parents of the male participants, $F(3,80)=4.57, p=.04$. These findings are summarized in Figure 1.

We next examined the mediating effect of phenotype on the association between biracial identity and self-esteem using stepwise multiple regression and guidelines established by Baron and Kenny (1986) and others (Frazier, Tix, \& Barron, 2004; Tix \& Frazier, 2005). We examined bivariate correlations between variables independently based on parents' racial heritage (i.e., Polynesian father vs. Polynesian mother) with subscale scores on the BIAS, as researchers have suggested taking into account 
Table 2. Bivariate Correlations of the Study's Variables by Parental Figure

\begin{tabular}{lcccccccc}
\hline Variable & 1 & 2 & 3 & 4 & 5 & 6 & 7 & 8 \\
\hline 1. AB-M & 1 & $.53^{* *}$ & $.46^{* *}$ & $.57^{* *}$ & .15 & .22 & $.35^{*}$ & -.21 \\
2. RIA-M & .23 & 1 & $.29^{*}$ & .20 & $.38^{* *}$ & .14 & $.28^{*}$ & -.07 \\
3. RB-M & .29 & $.53^{* *}$ & 1 & .06 & -.04 & .05 & -.01 & .12 \\
4. AB-P & $.58^{* *}$ & .06 & .14 & 1 & $.45^{* *}$ & $.68^{* *}$ & $.39^{* *}$ & $-.35^{* *}$ \\
5. RIA-P & .16 & $.44^{*}$ & $.35^{*}$ & $.56^{* *}$ & 1 & $.43^{* *}$ & .16 & -.12 \\
6. RB-P & .01 & .26 & $.39^{*}$ & .29 & $.58^{* *}$ & 1 & .16 & -.06 \\
7. PHEN & -.15 & -.16 & .08 & .04 & -.01 & .25 & 1 & $-.35^{*}$ \\
8. RSE & -.01 & -.05 & .11 & -.33 & -.21 & -.08 & .07 & 1 \\
\hline
\end{tabular}

Notes: Correlations above the diagonal represent participants reporting Polynesian fathers; correlations below the diagonal represent participants reporting Polynesian mothers. $\mathrm{AB}-\mathrm{M}=$ maternal acceptance and belonging; RIA-M = maternal racial identity achievement; RB-M = maternal racial behavior; $\mathrm{AB}-\mathrm{P}=$ paternal acceptance and belonging; RIA-P = paternal racial identity achievement; RB-P = paternal racial behavior; PHEN = phenotype; RSE = Rosenberg Self-Esteem Scale. ${ }^{*} p<.05 .{ }^{* *} p<.01$.

Figure 1. PARENTS' RaCial Group RATING $\times$ POLYNESIAN PARENTS REPRESENTS A SIGNIFICANT PARENTAL RATING $\times$ POLYNESIAN PARENTS INTERACTION, INDICATING THAT ALL PARTICIPANTS REPORTED HIGHER RACIAL IDENTIFICATION WITH THEIR POLYNESIAN THAN THEIR WHITE PARENT.

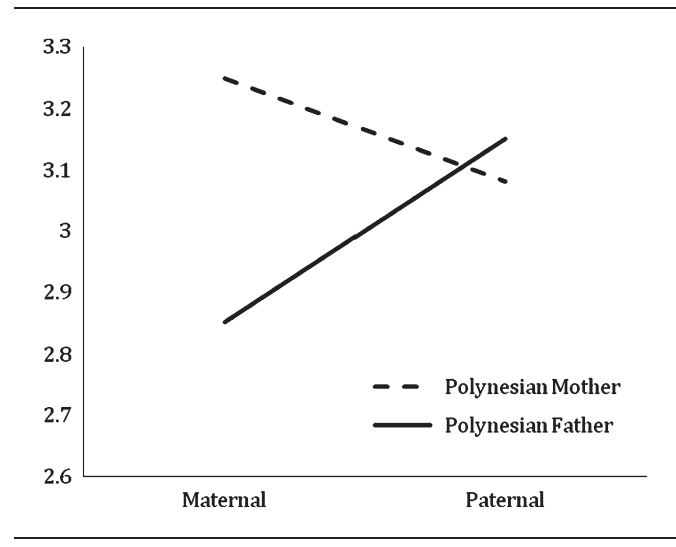

family structure in studies with multiracial samples (Coleman \& Carter, 2007; Crawford \& Alaggia, 2008). Observed correlations indicated that the conditions for mediation were only satisfied for participants reporting Polynesian fathers. Specifically, a significant relationship was also observed between Polynesian phenotype and self-esteem $(r=-.35, p=.04)$. To test for mediation (Baron \& Kenny, 1986; Frazier et al., 2004; Tix \& Frazier, 2005), four conditions need to be met. First, there must be a significant relationship between a predictor variable (paternal acceptance and belonging; Polynesian father) and criterion variable (self-esteem). This condition was met in that there was a significant correlation between paternal acceptance and belonging and lower self-esteem $(r=-.31$, $p=.009)$. Second, there must a significant relationship between predictor (paternal acceptance and belonging) and the proposed mediator variable (Polynesian phenotype). This condition was met for this mediator $(r=.39, p<.01)$. Third, there must be a significant relationship between the mediator variable (Polynesian phenotype) and the criterion variable (self-esteem). This condition was again met. Phenotype was significantly correlated with self-esteem $(r=-.35$, $p<.05)$. Fourth, the strength of the relationship between the predictor (paternal acceptance and belonging) and the outcome variable (selfesteem) decreases significantly when the mediator variable (Polynesian phenotype) is entered in the regression model. In this analysis, paternal acceptance and belonging was entered as a predictor (Step 1), Polynesian phenotype as a mediator variable (Step 2), with self-esteem as the criterion variable. Results showed that the relationship did not significantly decrease when Polynesian phenotype was entered into the model $(B=-.25, p=.08)$. Thus, there was no mediating effect for Polynesian phenotype between paternal acceptance and belonging and self-esteem (see Table 3).

\section{DISCUSSION}

The current study examined the relationships between self-esteem, racial identity, and phenotype among individuals who identified as biracial Polynesian and White. Results suggest 
Table 3. Mediation of Polynesian Phenotype Between the Relationship of Paternal Acceptance and Belonging (Polynesian Father) and Self-esteem

\begin{tabular}{lccc}
\hline Variable & $R^{2}$ Change & $B$ & $p$ Value \\
\hline Polynesian phenotype & & & \\
$\quad$ mediator & & & \\
$\quad$ Step 1 & .11 & -.36 & \\
Polynesian paternal & & & \\
$\quad$ acceptance and belonging & & & \\
$\quad$ Step 2 & .14 & -.25 & \\
Polynesian paternal & & & .08 \\
$\quad$ acceptance and belonging: & & & \\
$\quad$ Phenotype & & & \\
\hline
\end{tabular}

that participants were more likely to identify and affiliate with their Polynesian parents than their White parents. Furthermore, females reported higher levels on the BIAS with their Polynesian parents (both father and mother) than did male participants, indicating that female Polynesian/White persons identify and affiliate more with their Polynesian parents than do male Polynesian/White persons. Results also showed no mediating effect of self-reported phenotype between biracial identity and self-esteem.

On the basis of the research (Cooke, 1997; Pedrotti et al., 2008; Sue \& Sue, 2008) that shows that racial identity is linked to the selfesteem, psychological health, and well-being of multiracial individuals, this study sought to examine potential similar links from past research with another unique and less studied biracial group. This study has been able to further reduce the gap in the literature and advance the current understanding of multiracial individuals' psychological adjustment, specifically regarding the population of biracial Polynesians. Biracial Polynesian gender differences were also found, which adds to the existing research (Ramos et al., 2003; Shih \& Sanchez, 2005) related to physical characteristics and self-esteem.

There are several benefits from the results of this study. They can enable practitioners and researchers to explore, understand, and serve this population in different capacities. Specifically, counseling interventions and mental health programs can be developed to provide best practices to this underserved community related to their racial identity development and self-esteem. Findings from this study suggest that attending to Polynesian/White individuals' biracial identity and how it relates to family constellation and dynamics could guide intervention efforts. The significant negative association found between subjective Polynesian phenotype and self-esteem also suggests that attention to racialized messages from the self and others could be necessary. Additional investigation regarding Polynesian cultural values, gender expectations, and self-esteem would add to the existing literature.

Although the number of participants (84) was adequate for data analysis, the study could have enhanced statistical power if it had a larger sample size. Because of the limited time to gather data and possibly the cultural challenge of response time from the participants, the study generated a somewhat small size. Given the underrepresented population of Polynesians and biracial Polynesian/White people in the United States and the significant lack of research regarding this community, however, the sample size was sufficient to add to the multicultural psychology literature and potentially generate more interest to explore this group in the future.

Other potential areas for future research on Polynesians could be expanded further. For example, other states with Polynesian/White persons may yield different or consistent results, and future research can be beneficial by involving other regions to find Polynesian/White individuals. Because of statistical power issues, we were also unable to examine potential differences between Polynesian subgroups (e.g., Tongan and Samoan). Future research should examine such differences, as collapsing cultural subgroups in this study may have limited generalizability of results. In addition, intergroup biracial and multiracial Polynesians (i.e., Hawaiian/Samoan) is an area that substantially lacks research efforts regarding identity development and racial, cultural, and sociocultural factors related to the identity development. We were unable to collect data on participants' socioeconomic status related to occupation and salary. Future research should address socioeconomic status and class with future Polynesian communities and the impact it has on identity and self-esteem.

\section{REFERENCES}

Allen, G. E. K., \& Heppner, P. P. (2011). Religiosity, coping, and psychological well-being among Latter-Day Saint Polynesians in the U.S. Asian American Journal of Psychology, 2, 13 - 24. 
Baron, R. M., \& Kenny, D. A. (1986). The moderator-mediator variable distinction in social psychological research: Conceptual, strategic, and statistical considerations. Journal of Personality and Social Psychology, 51, 1173 - 1182.

Bernstein, R., \& Edwards, T. (2008). U.S. Census Bureau news: An older and more diverse nation by midcentury. Retrieved from http://www.census.gov/Press-Release/archives/ population/012496.html

Binning, K. R., Unzueta, M. M., Huo, Y. J., \& Molina, L. E. (2009). The interpretation of multiracial status and its relation to social engagement and psychological well-being. Journal of Social Issues, $65,35-49$.

Blascovich, J., \& Tomaka, J. (1991). Measures of self-esteem. Measures of personality and social psychological attitudes. San Diego, CA: Academic Press.

Brunsma, D. L., \& Rockquemore, K. A. (2001). The new color complex: Appearances and biracial identity. Identity, 1, $225-246$.

Brusa, N. K. (2008). A phenomenological study of the experience of biracial identity development in Black and White individuals (Doctoral dissertation). Retrieved from ProQuest database (AAT 3312832).

Choi-Misailidis, S. (2003). Multiracial-heritage awareness and personal affiliation: Development and validation of a new measure to assess identity in people of mixed race descent. (Unpublished doctoral dissertation). Fordham University, New York.

Coard, S. I., Breland, A. M., \& Raskin, P. (2001). Perceptions of and preferences for skin color, Black racial identification, and self-esteem among African Americans. Journal of Applied Social Psychology, 31, 2256 - 2274.

Cobb-Clark, D. A., \& Kossoudji, S. A. (2000). Mobility en el norte: The employment and occupational changes of unauthorized Latin American women. Social Science Quarterly, 81, $311-324$.

Coleman, V. H., \& Carter, M. (2007). Biracial self-identification: Impact on trait anxiety, social anxiety, and depression. Identity, 7, $103-114$.

Cooke, T. I. (1997). Biracial identity development: Psychosocial contributions to self-esteem and racial identity. Dissertation Abstracts International: Section B: The Sciences \& Engineering, $58,5669$.

Cooney, T. M., \& Radina, M. E. (2000). Adjustment problems in adolescence: Are multiracial children at risk? American Journal of Orthopsychiatry, 70, $433-444$.

Crawford, S. E., \& Alaggia, R. (2008). The best of both worlds? Family influences on mixed race youth identity development. Qualitative Social Work: Research and Practice, 7, 81 - 98.
Frazier, P. A., Tix, A. P., \& Barron, K. E. (2004). Testing moderator and mediator effects in counseling psychology research. Journal of Counseling Psychology, 51, 115 - 134.

Garriott, P. O., Love, K. M., \& Tyler, K. M. (2008). Anti-Black racism, self-esteem, and the adjustment of Whites students in higher education. Journal of Diversity in Higher Education, 1, 45 - 58.

Gillem, A. R., Cohn, L. R., \& Throne, C. (2001). Black identity in biracial Black/White people: A comparison of Jacqueline who refuses to be exclusively Black and Adolphus who wishes he were. Cultural Diversity \& Ethnic Minority Psychology, 7, 182 - 196.

Greene, A. L. (1994). Situational ethnicity effects: A comparison of biracial and monoracial adults. (Unpublished dissertation). Pacific Graduate School of Psychology, Palo Alto, CA.

Greenless, C. S., \& Saenz, R. (1999). Determinants of employment of recently arrived Mexican immigrant wives. International Immigration Review, $33,354-377$.

Hall, C. C. (1992). Please choose one: Ethnic identity choices for biracials. In M. P. P. Root (Ed.), Racially mixed people in America (pp. 250 - 264). Newbury Park, CA: Sage.

Helms, J. E. (1997). Implications of Behrens for the validity of the White Racial Identity Attitude Scale. Journal of Counseling Psychology, 44, $13-16$.

Jacobs, J. H. (1977). Black/White interracial families: Marital process and identity development in young children. (Unpublished doctoral dissertation). Wright Institute, Berkeley, CA.

Jacobs, J. H. (1992). Identity development in biracial children. In M. P. P. Root (Ed.), Racially mixed people in America. Newbury Park, CA: Sage.

Keith, V. M., Lincoln, K. D., Taylor, R. J., \& Jackson, J. S. (2010). Discriminatory experiences and depressive symptoms among African American women: Do skin tone and mastery matter? Sex Roles: A Journal of Research, 62, 48 - 59.

Kerwin, C., \& Ponterotto, J. G. (1995). Biracial identity development theory and research. In J. G. Ponterotto, J. M. Casas, L. A. Suzuki, \& C. M. Alexander (Eds.), Handbook of multicultural counseling (pp. 199 - 215). Newbury Park, CA: Sage.

Khanna, N. D. (2008). Living life in Black and White: Identity formation and negotiation among Black-White biracial Americans. (Doctoral dissertation). Retrived from ProQuest database (AAT 3279879).

Kich, G. K. (1992). The development process of asserting a biracial, bicultural identity. In M. P. P. Root (Ed.), Racially mixed people in America (pp. 304 - 317), Newbury Park, CA: Sage. 
Koot, W., \& Venema, P. U. (1985). Measurement of the notion of ethnic identity with children. Research in Education, 34, 9 - 32.

López, I. (2008). “'But you don't look Puerto Rican": The moderating effect of ethnic identity on the relation between skin color and self-esteem among Puerto Rican women. Cultural Diversity and Ethnic Minority Psychology, 14, $102-108$.

McCubbin, L. D., \& Dang, T. (2010). Native Hawaiian identity and measurement: An ecological perspective on indigenous identity development. In J. G. Ponterotto, J. M. Casas, L. A. Suzuki, \& C. M. Alexander (Eds.), Handbook of multicultural counseling (3rd ed.). Thousand Oaks, CA: Sage.

McCubbin, L. D., Ishikawa, M., \& McCubbin, H. I. (2007). Kanaka Maoli: Native Hawaiians and their testimony of trauma and resilience. In A. Marsella, J. Johnson, P. Watson, \& J. Gryczynski (Eds.), Ethnocultural perspectives on disaster and trauma: Foundations, issues and applications (pp. 271 - 298). New York: Springer.

Morganthau, T. (1995, February 13). What color is Black? Newsweek, 63 - 65.

Overmier, K. (1990). Biracial adolescents: Areas of conflict in identity formation. Journal of Applied Social Sciences, 14, 157 - 176.

Parham, T. A., \& Helms, J. E. (1985). Attitudes of racial identity and self-esteem of Black students: An exploratory study. Journal of Counseling Psychology, 28, $250-258$.

Pasion-Gonzales, L. M. (1994). Situational ethnicity effects: A comparison of biracial and monoracial adults. (Unpublished doctoral dissertation). Pacific Graduate School of Psychology, Los Angeles, CA.

Pedrotti, J. T., Edwards, L. M., \& Lopez, S. J. (2008). Working with multiracial clients in therapy: Bridging theory, research, and practice. Professional Psychology: Research and Practice, 39, $192-201$.

Phinney, J. S. (1992). The Multigroup Ethnic Identity Measure: A new scale for use with diverse groups. Journal of Adolescent Research, 7, 156 - 176.

Phinney, J. S. (1996). When we talk about American ethnic groups, what do we mean? American Psychologist, 51, 918 - 927.

Poston, W. S. C. (1990). The biracial identity development model: A needed addition. Journal of Counseling and Development, 69, $152-155$.

Ramos, B., Jaccard, J., \& Guilamo-Ramos, V. (2003). Dual ethnicity and depressive symptoms: Implications of being Black and Latino in the United States. Hispanic Journal of Behavioral Sciences, 25, 147 - 173.
Rockquemore, K. A., \& Brunsma, D. L. (2002). Beyond Black: Biracial identity in America. Thousand Oaks, CA: Sage.

Root, M. P. P. (1996). The multicultural experience: Racial borders as the new frontier. Thousand Oaks, CA: Sage.

Rosenberg, M. (1965). Society and the adolescent self-image. Princeton, NJ: Princeton University Press.

Shih, M., \& Sanchez, D. T. (2005). Perspectives and research on the positive and negative implications of having multiple racial identities. Psychological Bulletin, 131, 569 - 591.

Sobralske, M. (2006). Olakino Maika'i: Health care in Pacific Island culture. Journal of the American Academy of Nurse Practitioners, 18, 81 - 82.

Speight, S. L. (1996). Racial self-designation, racial identity, and self-esteem revisited. Journal of Black Psychology, 22, $37-52$.

Spickard, P. R. (1989). Mixed blood: Intermarriage and ethnic identity in twentieth-century America. Madison: University of Wisconsin Press.

Standen, B. C. (1996). Without a trace: The biracial Korean/White experience. In M. P. P. Root (Ed.), The multiracial experience: Racial borders as the new frontier (pp. 245 - 262). Newbury Park, CA: Sage.

Sue, D. W., \& Sue, D. (2008). Counseling the culturally diverse: Theory and practice. (5th ed.). New York: John Wiley \& Sons, Inc.

Suzuki-Crumly, J., \& Hyers, L. L. (2004). The relationship among ethnic identity, psychological well-being, and intergroup competence: An investigation of two biracial groups. Cultural Diversity and Ethnic Minority Psychology, 10, 137 - 150.

Telzer, E. H., \& Garcia, H. A. V. (2009). Skin color and self-perceptions of immigrant and U.S.-born Latinas: The moderating role of racial socialization and ethnic identity. Hispanic Journal of Behaivoral Sciences, 31, 357 - 374.

Thrasher, S. M. (1994). Well-being in a biracial sample: Racial identification and similarity in parents. (Unpublished doctoral dissertation). Boston University, Boston.

Tix, A. P., \& Frazier, P. A. (2005). Mediation and moderation of the relationship between intrinsic religiousness and mental health. Personality and Social Psychology Bulletin, 31, 295 - 306.

U.S. Census Bureau. (2009). Redistricting data (P.L. 94 - 171). Summary File for states, Table PL1.

Watt, S. K. (2006). Racial identity attitudes, womanist identity attitudes, and self-esteem in African American college women attending historically Black single-sex and coeducational institutions. Journal of College Student Development, 47, $319-334$. 